\title{
Short-term effects of joint mobilization with versus without voluntary movement in patients with chronic ankle instability: A single-blind randomized controlled trial
}

\author{
Hyunjoong Kim ${ }^{\mathrm{a}, \mathrm{b}}$, Seonghyeok Song ${ }^{c}$, Sangbong Lee ${ }^{c}$, Seungwon Lee ${ }^{\mathrm{d}, \mathrm{e}}$ \\ aSports Rehabilitation Center, The Better Hospital, Gwangju, Republic of Korea \\ bepartment of Physical Therapy, Gwangju Health University, Gwangju, Republic of Korea \\ 'Department of Physical Therapy, Graduate School of Sahmyook University, Seoul, Republic of Korea \\ dDepartment of Physical Therapy, College of Health Science and Social Welfare, Sahmyook University, Seoul, Republic of Korea \\ e Institute of SMART Rehabilitation, Sahmyook University, Seoul, Republic of Korea
}

\begin{abstract}
Objective: Joint mobilization for arthrokinematics altered by the positional fault of chronic ankle instability (CAI) is an effective intervention for stabilization. In this study, we compared the effects of ankle dorsi flexion range of motion (DFROM) and dynamic balance ability (DBA) in CAI patients via passive joint mobilization (PJM), a method traditionally performed in previous studies, and active joint mobilization (AJM), a method that can have a greater effect on cortical excitability with spontaneous movements.

Design: Single-blind two-arm randomized controlled trial

Methods: A total of 30 participants were registered: 15 each to the PJM and AJM groups. Each participant received a total of 10 intervention sessions, 10 minutes per session, 5 times a week for 2 weeks. PJM used Maitland's mobilization method to apply joint mobilization with talus in the posterior direction and AJM used an angular joint motion to induce patient's voluntary motion of medial malleolus anterior gliding and lateral malleolus posterior gliding, respectively. DFROM of the ankle was measured by using tape and DBA was evaluated by using the balance system.

Results: Significant improvement was observed after intervention in both the PJM and AJM groups except for the DBA-anterior and DBA-right variables of the PJM group. There were statistically significant differences between the AJM and PJM groups in the DFROM, DBA-anterior, DBA-posterior, and DBA-right variables.

Conclusions: The overall improvement of DFROM and DBA was found to be more effective in joint mobilization including voluntary movement. When it is accompanied by voluntary movement, it further affects the neuromuscular system of the ankle.
\end{abstract}

Key Words: Joint instability, Ankle injuries, Postural balance, Musculoskeletal manipulations, Joint mobilization

\section{Introduction}

Among musculoskeletal injuries, ankle sprains are common [1]. In addition, the recurrence rate of ankle sprain is high, and symptoms often persist [2]. Similarly, frequent sprains after the index injury cause chronic ankle instability (CAI) $[3,4]$. Symptoms caused by CAI are characterized by the recurrence of pain and swelling during activity and weakening of the muscles around the ankle joint [4].

CAI, which has a high recurrence rate and long-lasting discomfort, can be noted as a characteristic sensorimotor defect. This is a decreased conscious perception, indicating a defect in afferent somatosensory information and efferent motor control [5]. In the study of cortical excitability, there was a difference in cortical excitability

Received: Mar 3, 2021 Revised: Mar 14, 2021 Accepted: Mar 15, 2021

Corresponding author: Seungwon Lee (ORCID https://orcid.org/0000-0002-0413-0510)

Department of Physical Therapy, College of Health Science and Social Welfare, Sahmyook University

815 Hwarang-ro, Nowon-gu, Seoul 01795, Republic of Korea

Tel: (82 for International)-02- 3399-1630 Fax: 02- 3399-1639 E-mail: swlee@syu.ac.kr

This is an Open-Access article distributed under the terms of the Creative Commons Attribution Non-Commercial License (http://creativecommons.org/licenses/ by-nc/4.0) which permits unrestricted non-commercial use, distribution, and reproduction in any medium, provided the original work is properly cited.

Copyright (c) 2021 Korean Academy of Physical Therapy Rehabilitation Science 
and joint laxity between CAI patients and healthy adults, and it was reported that cortical excitability was decreased in ankle instability patients subjected to transcranial magnetic stimulation. This means that the chronic state of joint laxity has high cortical excitability, and it means that cortical excitability as well as joint laxity needs to be reduced $[6,7]$.

In other words, CAI has great influence on the nervous system, which acts as a modulator of body movement. Therefore, the main rehabilitation protocol for patients with CAI is to improve neuromuscular function. This can be explained by a decrease in joint position sense due to damage to the ankle ligament receptors [8] and peroneal nerve [9] resulting from the injury [10].

Among the conventional interventions for CAI, anterior to posterior talocrural joint mobilization effectively improves CAI and may show some neuromuscular mechanisms by increasing fibularis musculotendinous stiffness [11]. However, the effect of passive joint mobilization (PJM) by the therapist is limited to the neuromuscular mechanism as there is no active movement.

Therefore, active joint mobilization (AJM) is judged by the patient's active repetition accompanied by pain-free motion to sustained mobilization performed by the therapist and can have a greater influence on cortical excitability. This aims at the central nervous system level of motion corrected under the therapist's guidance, as re-education on pain-free motion patterns is implied in neuroscience theory [12-15].

In CAI patients, joint mobilization combined with voluntary movement will have more influence on the neuromuscular system than PJM, which corresponds to conventional joint mobilization. Therefore, in this study, the range of motion and balance ability are compared and verified to find out the effect according to with or without voluntary movement.

\section{Methods}

\section{Study design}

This single-blind two-arm parallel design randomized controlled trial included two evaluation sessions (baseline and post-intervention) and 10 intervention sessions (PJM and AJM). In the outcome measure, the primary variable was the dorsi flexion range of motion
(DFROM) of the ankle joint, while the secondary variable was dynamic balance ability (DBA).

\section{Participants}

Recruitment of potential participants was recruited by staff and students through the bulletin board of Gwangju Health University, Gwangju, Korea. Forty-four potential participants who diagnosed an ankle sprain were recruited; of them, 30 were ultimately enrolled in the study.

The inclusion criteria were: (a) self-reported instability and feeling of "giving way," (b) a history of sprains in only one ankle, (c) at least two sprains on the same side in the past 2 years, (d) Feeling different in sensation compared to an intact ankle, and (e) not receiving other treatment during the study [16].

The exclusion criteria included: (a) acute ankle sprain within the last 6 months, (b) a history of bilateral ankle injury, (c) bony injury related to ankle sprain, and (d) a history of surgery on the back or lower extremities [16].

Prior to the study, all participants were informed about the purpose and procedure in accordance with the ethical standards of the Declaration of Helsinki. Only those who voluntarily signed an informed consent form were enrolled.

\section{Randomization and blinding}

Participants were randomly and blindly assigned to the PJM and AJM groups using random allocation software (ver. 1.0; Isfahan University, Iran).

\section{Intervention}

The PJM and AJM interventions were performed on the affected foot for $10 \mathrm{~min}$ in each session by two physical therapists who have more than 5 years of clinical experience and have been trained in Orthopedic manual physical therapy. The participants received a total of 10 sessions five times a week for 2 weeks [17].

\section{Passive joint mobilization}

PJM uses Maitland's mobilization method, grade III (high amplitude in the end range of the joint and 1-s vibration in the middle range through linear motion in which tissue resistance is felt). The participant assumed a supine position, and the physical therapist held the talus with one hand and the tibia with the other hand and performed joint mobilization in the posterior direction 
with the hand holding the talus (Figure 1) [18].

\section{Active joint mobilization}

In the AJM, the participant bent their knees in the prone position. The physical therapist held the medial malleolus with one hand and the lateral malleolus with the other. At the same time, the physical therapist put the participant's soles against the sternum and pressed them in the plantar direction. At this time, the medial malleolus would glide in the anterior direction and the lateral malleolus would glide in the posterior direction. The first procedure passively recognizes participant's joint motion, while the second procedure involves the voluntary motion (Figure 2) [19-21].

\section{Outcomes}

Participants are enrolled in the study and evaluated for DFROM and DBA prior to intervention (baseline), and immediately after two weeks of intervention (postintervention).

\section{Dorsiflexion range of motion}

The DFROM of the ankle was measured using a weight-bearing lunge. The therapist placed a tape measure on the floor perpendicular to a flat wall without protrusion and affixed it to prevent motion. The second toe and heel of the participant's foot to be measured were placed parallel to the tape measure, and the non-measured foot was separated from the measuring foot as much as the individual's foot. The standard for placing the first second toe was $10 \mathrm{~cm}$ and bent until the knees touched the wall. The maximum range of ankle instep flexion was until the

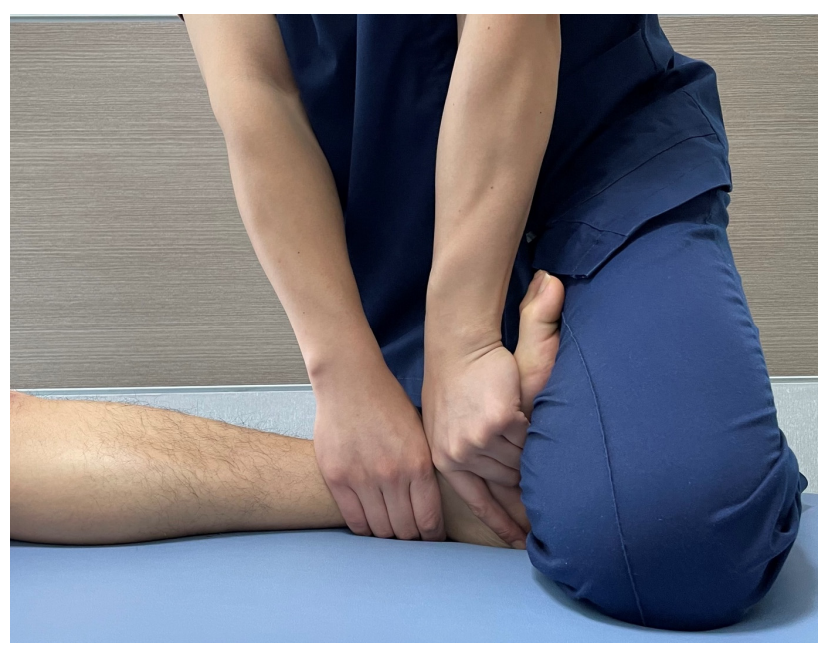

Figure 1. Passive joint mobilization heel reached without falling off the floor [22]. As a precaution, the trunk of the body should not be tilted forward and should be bent toward the wall only at the knee. If the knee could reach the wall during bending, the foot was moved forward, while if the knee easily touched the wall, the foot was moved backward. This measurement was performed three times for each of the left and right feet, and the average value of the measured values was recorded as the ankle angle.

The inter-rater reliability of DFROM has a high intraclass correlation coefficient of 0.99 [23], and minimal detectable change is from 1.1 to $1.5 \mathrm{~cm}$ [24].

\section{Dynamic balance ability}

DBA was evaluated with the participant in a standing position on both feet using the Biodex Balance System (Biodex Balance System; Biodex Medical Systems Inc., USA). The balance measurement equipment consisted of a fixed circular scaffold with a sensor that detects anterior/posterior, left/right motion, a monitor that can visually check and match a target, a computer for data transmission and analysis, and a computer for analysis data output. It consisted of four main types, including printers. The higher the score, the better the balance ability. At the time of the measurement, both arms were collected on the chest, the center of gravity of the body was moved to maintain it according to the target, and the

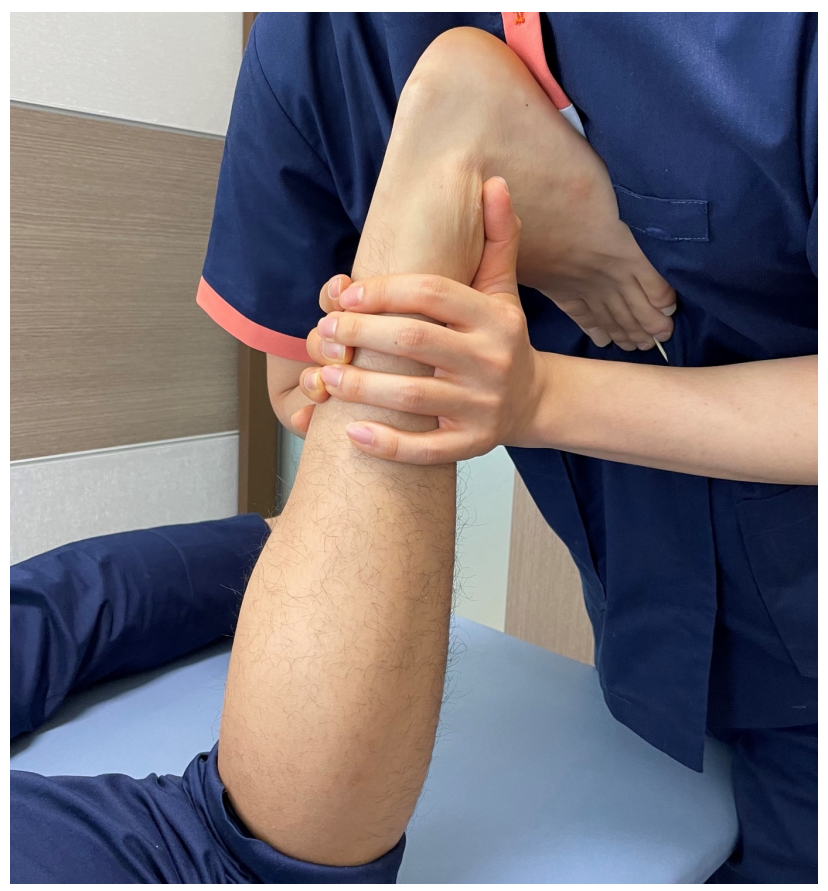

Figure 2. Active joint mobilization 
foot position was carefully measured to prevent movement [25].

In the evaluation of the DBA, the scaffold was not fixed, and scaffold instability could be adjusted in various stages from 1 to 12 (least stable to most stable). In this study, DBA was measured by setting the level of stool movement to one of eight stages. As in the static balance ability evaluation, the foot position was not changed, but the task time and route were recorded by setting the target point and moving the body center to reach the point. Measurements were made twice for $20 \mathrm{~s}$ with a 10-s break between them. Measurement of DBA using the Biodex Balance System was reported to have an ICC of 0.42 to 0.80 with appropriate intratester reliability [26].

\section{Sample size}

In the study by Cruz-Díaz, Lomas Vega (16), the sample size was calculated by changing the range of motion before and immediately after joint mobilization in CAI patients. The calculated Cohen's d was 1.36, and when two groups and power were set to 0.95 , using G*power 3.1 (G-power 3.1; Heinrich-Heine-Universität Düsseldorf, Germany), 26 samples were required. A total of 30 participants were enrolled in the study according to expected dropout and the central limit theorem.

\section{Statistical analysis}

All statistical analyses were performed using IBM SPSS Statistics version 25.0 (SPSS 25.0; IBM Corp., USA). The homogeneity test was performed using the chi-squared test (categorical variables) and independent t-test (continuous variables). An independent t-test was used to verify the effect of the difference between groups, while a paired t-test was used to determine the difference before versus after the interventions. Cohen's $\mathrm{d}$ and partial eta squared $\left(\eta_{P}^{2}\right)$ were used to determine the effect size of the treatment. $\eta_{P}^{2}$ was calculated using repeated measures analysis of variance (RM ANOVA). All statistical significance levels $(\alpha)$ were set at 0.05 .

\section{Results}

This study was conducted between April and June 2019. A total of 30 participants were recruited, and there were no dropouts (Figure 3). Table 1 presents the participants' general characteristics. There were no significant intergroup differences.

\section{Dorsiflexion range of motion}

There was statistically significant improvement in the PJM $(\mathrm{d}=-1.14, \mathrm{P}<0.001)$ and AJM $(\mathrm{d}=-2.90, \mathrm{P}<$ $0.001)$ groups before versus after the intervention. More significant improvement was noted in the AJM group than in the PJM group $\left(\eta_{P}^{2}=0.330, \mathrm{P}<0.01\right.$; Table 2).

\section{Dynamic balance ability}

In DBA-total, the difference before versus after the intervention was significantly improved in the PJM $(\mathrm{d}=$ $-1.33, \mathrm{P}<0.001)$ and AJM $(\mathrm{d}=-1.61, \mathrm{P}<0.001)$ groups. There was no significant intergroup difference $\left(\eta_{P}^{2}=0.047, \mathrm{P}>0.05\right.$; Table 2).

In DBA-anterior, the PJM group showed no significant improvement $(\mathrm{d}=-0.71, \mathrm{P}>0.05)$, whereas the AJM group showed significant improvement $(\mathrm{d}=-2.60, \mathrm{P}<0.001)$. Therefore, the AJM group showed significantly greater improvement than the PJM group $\left(\eta_{P}^{2}=0.434, \mathrm{P}<0.001\right.$; Table 2).

Table 1. Participants' general characteristics $(n=30)$

\begin{tabular}{llll}
\hline & PJM $(\mathbf{n}=\mathbf{1 5})$ & AJM $(\mathbf{n}=\mathbf{1 5})$ & $\boldsymbol{\chi}^{\mathbf{2}} / \mathbf{t}$ \\
\hline Sex $($ male/female $)$ & $9 / 6$ & $7 / 8$ & 0.536 \\
Age $($ years $)$ & $24.60 \pm 2.72$ & $22.87 \pm 2.39$ & 1.855 \\
Height $(\mathrm{cm})$ & $166.27 \pm 8.76$ & $167.47 \pm 10.41$ & -0.342 \\
Weight $(\mathrm{kg})$ & $64.20 \pm 14.29$ & $68.20 \pm 16.64$ & -0.706 \\
BMI $\left(\mathrm{kg} / \mathrm{m}^{2}\right)$ & $22.96 \pm 3.16$ & $23.96 \pm 3.50$ & -0.821 \\
\hline
\end{tabular}

Values are presented as mean \pm standard deviation or number.

AJM: active joint mobilization, BMI: body mass index, PJM: passive joint mobilization. 


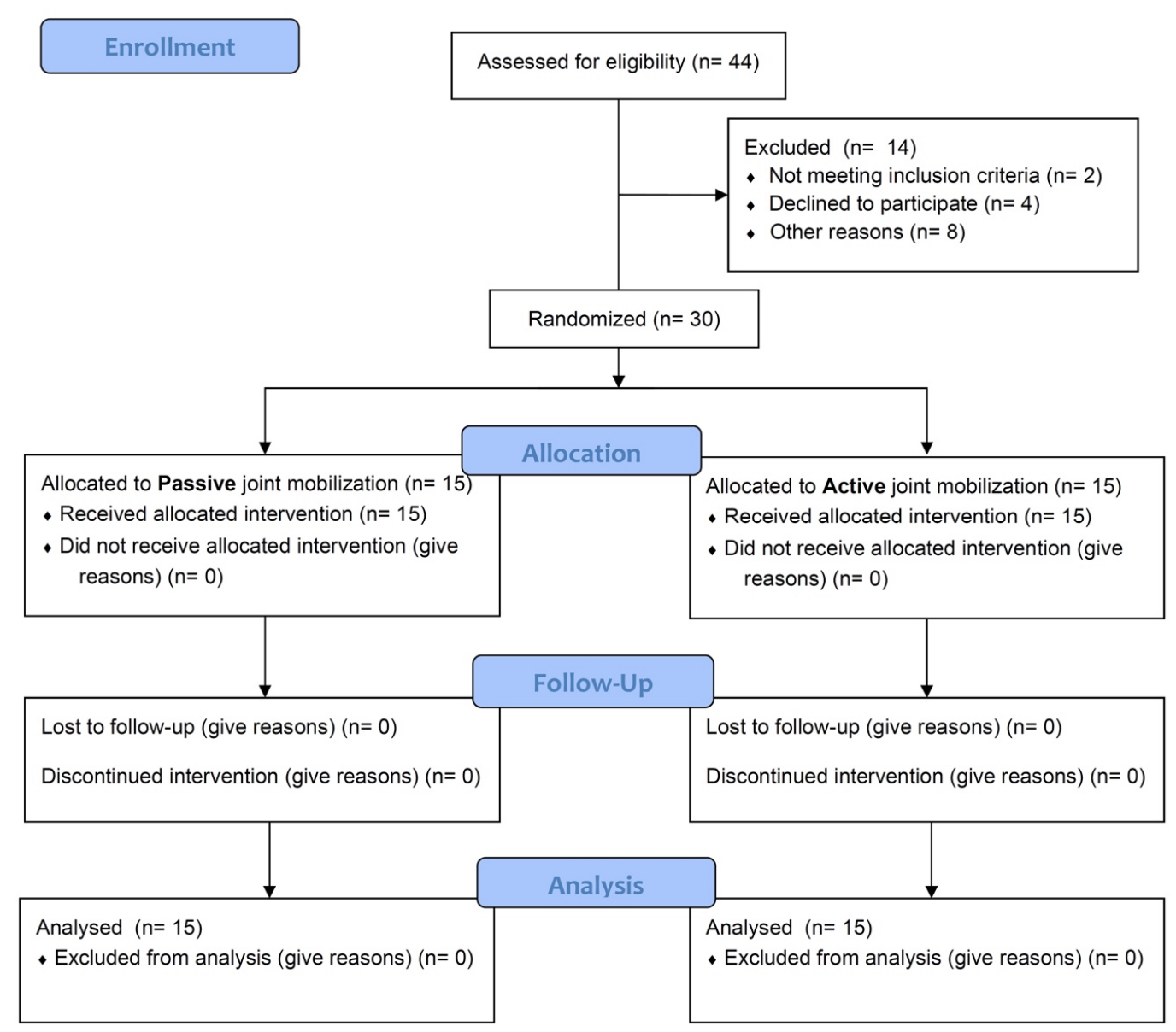

Figure 3. CONSORT (Consolidated Standards for Reporting of Trials) study flow diagram

In DBA-posterior, significant improvement was seen in both the PJM group $(\mathrm{d}=-0.74, \mathrm{P}<0.01)$ and the AJM group $(\mathrm{d}=-1.84, \mathrm{P}<0.001)$. The AJM group showed greater improvement than the PJM group $\left(\eta_{P}^{2}=\right.$ $0.369, \mathrm{P}<0.001$; Table 2).

In DBA-left, significant improvement was seen in both the PJM group $(\mathrm{d}=-1.55, \mathrm{P}<0.01)$ and the AJM group $(\mathrm{d}=-1.73, \mathrm{P}<0.001)$. There was no significant intergroup difference $\left(\eta_{P}^{2}=0.010, \mathrm{P}>0.05\right.$; Table 2$)$.

In DBA-right, the PJM group did not show any significant improvement $(\mathrm{d}=-0.65, \mathrm{P}>0.05)$, whereas the AJM group showed significant improvement $(\mathrm{d}=-$ 2.23, $\mathrm{P}<0.001)$. Significant differences were found before versus after treatment, but a separate sub-analysis (repeated-measures analysis of variance) showed more significant improvement in the AJM group than in the PJM group $\left(\mathrm{F}=8.321, \eta_{P}^{2}=0.229, \mathrm{P}<0.01\right.$; Table 2$)$.

\section{Discussion}

In this study, we compared the effects on ankle DFROM and DBA in CAI patients via PJM, a method traditionally performed in previous studies, and AJM, a method that can have a greater effect on neuromuscular system with voluntary movements.

After PJM and AJM were administered a total of 10 times to CAI patients, significant improvement was observed after the intervention in both groups except DBA-anterior and DBA-right in the PJM group. In addition, significantly greater improvement was noted in AJM than in PJM in DFROM, DBA-anterior, DBAposterior, and DBA-right. Joint mobilization had a large effect on each dependent variable $\left(\eta_{P}^{2}>0.14\right)$ [27] of DFROM, DBA-anterior, DBA-posterior, and DBA-right.

Significant improvement in ankle DFROM showed a large effect $(\mathrm{d}>0.80)$ [28] in the PJM and AJM groups. These results are similar to those of previous studies that showed significant improvement when performing 
Table 2. Comparison of treatment effects before versus after PJM and AJM ( $n=30)$

\begin{tabular}{|c|c|c|c|c|c|c|}
\hline \multirow[t]{2}{*}{ Variables } & \multicolumn{2}{|l|}{ PJM (n = 15) } & \multicolumn{2}{|l|}{ AJM (n = 15) } & \multirow[t]{2}{*}{ t $(95 \%$ CI $)$} & \multirow[t]{2}{*}{$\eta_{P}^{2}$} \\
\hline & Mean \pm SD & d & Mean \pm SD & d & & \\
\hline \multicolumn{7}{|l|}{ DFROM } \\
\hline Baseline & $6.50 \pm 1.32$ & -1.14 & $6.35 \pm 1.07$ & -2.90 & $\begin{array}{l}0.336 \\
(-0.751,1.046)\end{array}$ & 0.330 \\
\hline Post-intervention & $7.94 \pm 1.15$ & & $9.45 \pm 1.06$ & & $\begin{array}{l}-3.741^{\dagger}(-2.340 \\
-0.684)\end{array}$ & \\
\hline $\mathrm{t}(95 \% \mathrm{CI})$ & $-5.551^{\ddagger}(-$ & $,-0.880)$ & $-8.491^{\ddagger}(-$ & $-2.311)$ & & \\
\hline \multicolumn{7}{|l|}{ DBA-Total } \\
\hline Baseline & $22.01 \pm 3.16$ & -1.33 & $23.07 \pm 3.45$ & -1.61 & $\begin{array}{l}-0.872 \\
(-3.529,1.422)\end{array}$ & 0.047 \\
\hline Post-intervention & $26.25 \pm 3.21$ & & $28.50 \pm 3.28$ & & $\begin{array}{l}-1.893 \\
(-4.672,0.184)\end{array}$ & \\
\hline $\mathrm{t}(95 \% \mathrm{CI})$ & $-5.670^{\ddagger}(-$ & $-2.635)$ & $-7.971^{\ddagger}(-$ & $-3.968)$ & & \\
\hline \multicolumn{7}{|l|}{ DBA-Anterior } \\
\hline Baseline & $24.72 \pm 1.91$ & -0.71 & $24.34 \pm 3.70$ & -2.60 & $\begin{array}{l}0.352 \\
(-1.822,2.578)\end{array}$ & 0.434 \\
\hline Post-intervention & $26.64 \pm 3.35$ & & $32.43 \pm 1.84$ & & $\begin{array}{l}-5.860^{\ddagger}(-7.807 \\
-3.763)\end{array}$ & \\
\hline $\mathrm{t}(95 \% \mathrm{CI})$ & $-1.931(-4$ & $0.213)$ & $-9.181^{\ddagger}(-$ & $-6.199)$ & & \\
\hline \multicolumn{7}{|l|}{ DBA-Posterior } \\
\hline Baseline & $24.73 \pm 3.01$ & -0.74 & $24.98 \pm 3.54$ & -1.84 & $\begin{array}{l}-0.204 \\
(-2.703,2.213)\end{array}$ & 0.369 \\
\hline Post-intervention & $26.79 \pm 2.30$ & & $31.13 \pm 3.11$ & & $\begin{array}{l}-4.342^{\ddagger}(-6.389 \\
-2.293)\end{array}$ & \\
\hline $\mathrm{t}(95 \% \mathrm{CI})$ & $-3.480^{\dagger}(-$ & $,-0.787)$ & $-7.484^{\ddagger}(-$ & $-4.386)$ & & \\
\hline \multicolumn{7}{|l|}{ DBA-Left } \\
\hline Baseline & $25.59 \pm 2.29$ & -1.55 & $26.07 \pm 3.18$ & -1.73 & $\begin{array}{l}-0.483 \\
(-2.559,1.582)\end{array}$ & 0.010 \\
\hline Post-intervention & $30.07 \pm 3.47$ & & $31.27 \pm 2.81$ & & $\begin{array}{l}-1.046 \\
(-3.572,1.157)\end{array}$ & \\
\hline $\mathrm{t}(95 \% \mathrm{CI})$ & $-3.995^{\dagger}(-$ & $,-2.051)$ & $-6.650^{\ddagger}(-$ & $-3.523)$ & & \\
\hline \multicolumn{7}{|l|}{ DBA-Right } \\
\hline Baseline & $36.07 \pm 1.91$ & -0.65 & $27.25 \pm 2.94$ & -2.23 & $\begin{array}{l}9.760^{\ddagger} \\
(6.970,10.674)\end{array}$ & 0.229 \\
\hline Post-intervention & $38.15 \pm 4.02$ & & $33.01 \pm 1.96$ & & $\begin{array}{l}4.447^{\ddagger} \\
(2.769,7.498)\end{array}$ & \\
\hline $\mathrm{t}(95 \% \mathrm{CI})$ & $-1.920(-4$ & $0.242)$ & $-8.416^{\ddagger}(-$ & $-4.294)$ & & \\
\hline
\end{tabular}

Values are presented as mean \pm standard deviation.

AJM: active joint mobilization, CI: confidence interval, DBA: dynamic balance ability, DFROM: dorsiflexion range of motion, PJM: passive joint mobilization.

${ }^{*} \mathrm{P}<0.05,{ }^{\dagger} \mathrm{P}<0.01,{ }^{\dagger} \mathrm{P}<0.001$, statistically significant difference.

anterior to posterior talocrural joint mobilization in CAI patients [18, 29]. In addition, in the case of voluntary movements, the same results as those of previous studies were obtained [30, 31]. The minimal detectable change of DFROM for CAI patients reported in previous studies was reportedly $0.85 \mathrm{~cm}$ [32], which supports the results 
of this study. This is the basis for the fact that the talus was glide from anterior to posterior with joint mobilization, which is the same method as the previous studies.

The result of the improved ankle DFROM hypothesized that the anterior position fault of the talus changed the arthrokinematic (posterior talar glide) [33]. Therefore, the PJM and AJM involved posterior gliding of the talus and induced significant improvement.

In the DBA variables, the PJM and AJM groups showed significant improvement and had a moderate to large effect $(0.50<\mathrm{d}<0.80)$. This is similar to the results of Tomruk, Tomruk [34] that ankle joint mobilization with movement in dynamic balance showed significant improvement in postural control. In addition, a number of studies reported significant differences in the star excursion balance test, a variable that can indicate DBA, similar to how AJM showed significant improvement over PJM [16, 35, 36].

In a review article, AJM was effective and widely implemented in musculoskeletal pathologies and dysfunctions of various peripheral joints [12]. Another study reported a difference in the relationship between cortical excitability and joint laxity between healthy adults and those with CAI [7]. This means that the DBA improvement noted in this study affects the movement pattern changed by ankle instability and thus can escape from the chronic state. In a functional near-infrared spectroscopy study, supplementary motor areas (an important structure for motor planning and movement strategies) in CAI patients require activation compared to healthy adults [37].

The main limitation of this study is that its participants were recruited from universities and of similar young age. It was difficult to recruit a large number of participants due to the single-center design, and it may be difficult to generalize our results to other populations. In future research, hospitals or specific sports groups should also be recruited, and more participants need to be recruited and generalized. And finally, additional brain imaging studies are needed to demonstrate cortical excitability that occurs through voluntary movements.

\section{Conclusion}

In conclusion, joint mobilization may be effective at decreasing ankle dorsiflexion and reducing dynamic balance, characteristics of patients with CAI. However, using functional variables such as DBA, it was inferred that joint mobilization using voluntary movements can further stimulate cortical excitability in postural control. As in the results of this study, when a voluntary movement was made, dynamic balance was significantly improved.

\section{Conflict of interest}

The researcher claims no conflicts of interest.

\section{References}

1. Doherty C, Delahunt E, Caulfield B, Hertel J, Ryan $\mathrm{J}$, Bleakley $\mathrm{C}$. The incidence and prevalence of ankle sprain injury: a systematic review and meta-analysis of prospective epidemiological studies. Sports Med. 2014;44:123-40.

2. Roos KG, Kerr ZY, Mauntel TC, Djoko A, Dompier TP, Wikstrom EA. The epidemiology of lateral ligament complex ankle sprains in National Collegiate Athletic Association sports. Am J Sports Med. 2017;45:201-9.

3. Al-Mohrej OA, Al-Kenani NS. Chronic ankle instability: Current perspectives. Avicenna J Med. 2016;6:103.

4. Hertel J. Functional anatomy, pathomechanics, and pathophysiology of lateral ankle instability. J Athl Train. 2002;37:364.

5. Hertel J. Sensorimotor deficits with ankle sprains and chronic ankle instability. Clin Sports Med. 2008;27: 353-70, vii.

6. Pietrosimone BG, Gribble PA. Chronic ankle instability and corticomotor excitability of the fibularis longus muscle. J Athl Train. 2012;47:621-6.

7. Needle AR, Palmer JA, Kesar TM, Binder-Macleod SA, Swanik CB. Brain regulation of muscle tone in healthy and functionally unstable ankles. J Sport Rehabil. 2013;22:202-11.

8. Zech A, Hubscher M, Vogt L, Banzer W, Hansel F, Pfeifer K. Neuromuscular training for rehabilitation of sports injuries: a systematic review. Med Sci Sports Exerc. 2009;41:1831-41.

9. Nitz AJ, Dobner JJ, Kersey D. Nerve injury and grades II and III ankle sprains. Am J Sports Med. 1985;13:177-82. 
10. Konradsen L, Magnusson P. Increased inversion angle replication error in functional ankle instability. Knee Surg Sports Traumatol Arthrosc. 2000;8:246-51.

11. Cain MS, Kyeongtak S, Blackburn JT, Kimmery M, Erik AW. The Immediate Effects of Ankle Joint Mobilization on Ankle Musculotendinous Stiffness in Individuals With Chronic Ankle Instability. International Journal of Athletic Therapy and Training. 2021;26:106-10.

12. Hing W, Bigelow R, Bremner T. Mulligan's Mobilization with Movement: A Systematic Review. J Man Manip Ther. 2009;17:E39-E66.

13. Hing W. The Mulligan concept of manual therapy. Sydney: Churchill Livingstone; 2015.

14. Myers KM, Davis M. Behavioral and neural analysis of extinction. Neuron. 2002;36:567-84.

15. Zusman M. Mechanisms of musculoskeletal physiotherapy. Physical Therapy Reviews. 2004;9:39-49.

16. Cruz-Diaz D, Lomas Vega R, Osuna-Perez MC, Hita-Contreras F, Martinez-Amat A. Effects of joint mobilization on chronic ankle instability: a randomized controlled trial. Disabil Rehabil. 2015;37:601-10.

17. LeClaire JE, Wikstrom EA. Massage for Postural Control in Individuals With Chronic Ankle Instability. Athletic training \& sports health care. 2012;4:213-9.

18. Hoch MC, Andreatta RD, Mullineaux DR, English RA, Medina McKeon JM, Mattacola CG, et al. Twoweek joint mobilization intervention improves selfreported function, range of motion, and dynamic balance in those with chronic ankle instability. J Orthop Res. 2012;30:1798-804.

19. Vicenzino B, Branjerdporn M, Teys P, Jordan K. Initial changes in posterior talar glide and dorsiflexion of the ankle after mobilization with movement in individuals with recurrent ankle sprain. J Orthop Sports Phys Ther. 2006;36:464-71.

20. Hoch MC, McKeon PO. The effectiveness of mobilization with movement at improving dorsiflexion after ankle sprain. J Sport Rehabil. 2010;19:226-32.

21. Kim Y, Lee G. Immediate Effects of Angular Joint Mobilization (a New Concept of Joint Mobilization) on Pain, Range of Motion, and Disability in a Patient with Shoulder Adhesive Capsulitis: A Case
Report. Am J Case Rep. 2017;18:148-56.

22. Hoch MC, McKeon PO. Normative range of weight-bearing lunge test performance asymmetry in healthy adults. Man Ther. 2011;16:516-9.

23. Bennell KL, Talbot RC, Wajswelner H, Techovanich W, Kelly DH, Hall AJ. Intra-rater and inter-rater reliability of a weight-bearing lunge measure of ankle dorsiflexion. Aust J Physiother. 1998;44:175-80.

24. Konor MM, Morton S, Eckerson JM, Grindstaff TL. Reliability of three measures of ankle dorsiflexion range of motion. Int J Sports Phys Ther. 2012;7:279-87.

25. Kim KJ, Heo M. Effects of virtual reality programs on balance in functional ankle instability. J Phys Ther Sci. 2015;27:3097-101.

26. Perron M, Hebert LJ, McFadyen BJ, Belzile S, Regniere M. The ability of the Biodex Stability System to distinguish level of function in subjects with a second-degree ankle sprain. Clin Rehabil. 2007;21:73-81.

27. Cohen J. Eta-Squared and Partial Eta-Squared in Fixed Factor Anova Designs. Educational and Psychological Measurement. 1973;33:107-12.

28. Cohen J. Statistical power analysis for the behavioral sciences 2nd edn. Erbaum Press ,NJ, USA

29. Hoch MC, McKeon PO. Joint mobilization improves spatiotemporal postural control and range of motion in those with chronic ankle instability. J Orthop Res. 2011;29:326-32.

30. Marron-Gomez D, Rodriguez-Fernandez AL, MartinUrrialde JA. The effect of two mobilization techniques on dorsiflexion in people with chronic ankle instability. Phys Ther Sport. 2015;16:10-5.

31. Powden CJ, Hogan KK, Wikstrom EA, Hoch MC. The effect of 2 forms of talocrural joint traction on dorsiflexion range of motion and postural control in those with chronic ankle instability. J Sport Rehabil. 2017;26:239-44.

32. McKeon PO, Wikstrom EA. Sensory-targeted ankle rehabilitation strategies for chronic ankle instability. Med Sci Sports Exerc. 2016;48:776-84.

33. Denegar CR, Hertel J, Fonseca J. The effect of lateral ankle sprain on dorsiflexion range of motion, posterior talar glide, and joint laxity. J Orthop Sports 
Phys Ther. 2002;32:166-73.

34. Tomruk M, Soysal Tomruk M, Alkan E, Gelecek N. Immediate Effects of Ankle Joint Mobilization With Movement on Postural Control, Range of Motion, and Muscle Strength in Healthy Individuals: A Randomized, Sham-Controlled Trial. J Sport Rehabil. 2020;29:1060-8.

35. Someeh M, Norasteh AA, Daneshmandi H, Asadi A. Immediate effects of Mulligan's fibular repositioning taping on postural control in athletes with and without chronic ankle instability. Phys Ther Sport. 2015;16:135-9.

36. Shi X, Han J, Witchalls J, Waddington G, Adams R. Does treatment duration of manual therapy influence functional outcomes for individuals with chronic ankle instability: A systematic review with meta-analysis? Musculoskelet Sci Pract. 2019;40:87-95.

37. Rosen AB, Yentes JM, McGrath ML, Maerlender AC, Myers SA, Mukherjee M. Alterations in Cortical Activation Among Individuals With Chronic Ankle Instability During Single-Limb Postural Control. J Athl Train. 2019;54:718-26. 